\title{
Mitigating the Impact of Solid Wastes in Urban Centres in Nigeria
}

\author{
Napoleon S. Momodu, Kingsley O. Dimuna** and Joan E. Dimuna ${ }^{* * * *}$ \\ *Department of Building, **Department of Architecture and ***c/o Kingsley O. Dimuna \\ Ambrose Alli University, P.M.B. 14 Ekpoma, Edo State, Nigeria \\ *GSM: +234-8057917585, **Gsm: +234-8033588987, **Gsm: +234-8053311686; ** \\ E-mail: kodimuna@yahoo.com
}

KEYWORDS Mitigating. Impact. Solid Wastes. Urban Centre. Nigeria

\begin{abstract}
Nigeria's major urban centres are today grappling with the problems caused by mounting heaps of solid wastes from their environments. This paper undertakes a study of the solid waste build up phenomenon with a view toward finding ameliorative measures that would help reduce their negative effects on urban beautification and sanitation. And hopefully, to provide insights into easing, reducing, minimizing and avoiding the evolving solid, waste encroachment of city streets and roads, particularly in areas of uncontrolled growth and developmenttypifying cities in Nigeria .
\end{abstract}

\section{INTRODUCTION}

Solid wastes comprise all the wastes arising from human and animal activities that are normally solid, discarded as useless or unwanted. Also included are by- products of process lines or materials that may be required by law to be disposed of (Okecha 2000). Solid waste can be classified in a number of ways, on the basis of sources, environmental risks, utility and physical property. On the basis of source, solid wastes are again classified as: Municipal Solid Wastes, Industrial Solid Wastes and Agricultural Solid Wastes.

Nigeria's major urban centres are today fighting to clear mounting heaps of solid waste from their environments. These strategic centres of beauty, peace and security are being overtaken by the messy nature of over flowing dumps unattended heaps of solid wastes emanating from household or domestic or kitchen sources, markets, shopping and business centres. City officials appear unable to combat unlawful and haphazard dumping of hazardous commercial and industrial wastes which are a clear violation of the clean Air and Health Edicts in our environmental sanitation laws, rules and regulation.

Refuse generation and its likely effects on the health, quality of environment and the urban landscape have become burning national issues in Nigeria today. All stakeholders concern with the safety and the beautification of our environment have come to realise the negative consequences of uncleared solid human wastes found in residential neighbourhoods, markets, schools, and central business districts in our cities. These solid wastes have become recurring features in our urban environment. It is no longer in doubt that our cities are inundated with the challenges of uncleared solid wastes. As a result, urban residents are often confronted with the hazardous impact to their collective health and safety. The hue and cry over the health consequences of exposed and fermenting rubbish have not been quantified, although their impact is noticeable, especially in times of epidemic in congested activity nucleicivic centres, CBDS, neigbhourhoods, etc.

A United Nations Report (August 2004) noted with regret that while developing countries are improving access to clean drinking water they are falling behind on sanitation goals. At one of its summit in 2000 (Uwaegbelun 2004) revealed that The World Health Organization(WHO 2004) and United Nations International Children Education Fund- (UNICEF 2004) joint report in August 2004 that: "about 2.4 billion people will likely face the risk of needless disease and death by the target of 2015 because of bad sanitation". The report also noted that bad sanitation - decaying or non-existent sewage system and toilets- fuels the spread of diseases like cholera and basic illness like diarrhea, which kills a child every 21 seconds. The hardest hit by bad sanitation is rural poor and residents of slum areas in fast-growing cities, mostly in Africa and Asia .

In 1992, the "Earth Summit" succeeded in 
alerting the conscience of the world to the urgency of achieving environmentally sustainable development. The Summit asserted that if we know enough to act today, then we must also find answers to many tough conceptual and technical questions that have remained unsolved over time. It affirms that rapid urbanization in developing world if ignored can be a threat to health, the environment and urban productivity. Cities are the engines of economic growth, but the environmental implications of such growth need to be assessed and managed better. The critical and most immediate problems facing developing countries and their cities are the health impact of urban pollution that are derived from inadequate water services, poor urban and industrial waste management, as well as air pollution, especially from particulates.

Among the pressing environmental and public health issues in Nigeria today is the problem of solid waste generation and disposal. The problem of solid waste is a historical one because man's existence is inextricably linked to the generation of waste. The problem is becoming intractable as many cities in developing countries cannot keep pace with urbanization, pollution, and the increasingly concomitant generation of garbage due to changing life styles and consumption patterns.

The mountainous heaps of solid wastes that deface Nigerian cities and the continuous discharge of industrial contaminants into streams and rivers without treatment motivated the federal government of Nigeria to promulgate Decree 58 for the establishment of Federal Environmental Protection Agency (FEPA) on 30 December 1988 (Federal Military Government 1988). A national policy on the environment was formed and the goals of the policy include: to secure for all Nigerians a quality of environment adequate for their health and well being; to raise public awareness and promote understanding of the essential linkages between the environment and development; and to encourage individual and community participation in environmental protection and improvement efforts (FEPA 1989). As regards the solid waste sector, the specific actions desired include collection and disposal of solid waste in an environmentally safe manner; setting up and enforcement of laws, regulations, and standards; encouragement of public participation; environment monitoring and imposition of penalties on defaulters to encourage compliance (FEPA 1989; FRN 1991).
In spite of the formulation of FEPA and a national environmental policy, the environment has not been adequately protected. Interest is mainly on aesthetics, which is rarely achieved (Agunwanba 1998). Wastes collection is irregular and restricted to the major cities. Improperly sited open dumps deface several cities, thereby endangering public health by encouraging the spread of odors and diseases, uncontrolled recycling of contaminated goods and pollution of water sources (Adegoke 1989 Singh 1998).

Sadly, there seems a resignation to the unremitting solid wastes build up by the relevant authorities, where such bodies exist at all. However, in reactions to the inescapable environmental impact of delay in solid wastes removal, the federal government for example, introduced the monthly environmental sanitation in the early seventies. There from the States and Local Governments were expected to take a cue and evolve their own solid wastes management (SWM) strategies based on the peculiarities of their environment.

Each state had in the process of mitigating urban solid wastes, set up Wastes Management Boards (WMB) in attempts to tackle the occurrence of wastes and their hazards to society as a whole. While the unhealthy aspects of abandoned solid wastes can be contained, the more avoidable features of blocked drains, traffic impedance and floods have yet to be fully tackled. One resonant feature common in the wastes build-up and emanating environmental degradation scenarios is the high cost or capital intensive nature of its amelioration as well as tackling the solid wastes menace. It requires a lot of financial and human capital to minimize and attempt to eradicate the adverse effects of exposed and untreated solid wastes in our urban centres.

It is expected that government would in due course arrive at the means to combat solid wastes and reduce their negative impact on area residents and the perception of our cities as being dirty, chaotic, and full of traces of rotting or fermenting garbage that emit odours harmful to the human body. Obviously, the timely removal of accumulated solid wastes require much more than our governments at all levels are presently engaged in. Further plans, policies and programs would need to be put on a more permanent basis in order to combat the dastardly effects of 
environmental degradation. Understandably, it would require effective mobilization of resources such as involving all stakeholders in regular counter measure to suppress uncontrolled solid wastes generation and irregular disposal outside city confines altogether.

\section{Statement of Problem}

\section{A Socio-cultural Perspective / Dilemma}

Incidentally, from a pragmatic point of view, our customs and traditions have not helped in mobilizing for the environmental protection and safety; neighborhood planning; and beautification of our core activity areas. Otherwise, had there been a system of collective action to keep our surroundings clean; and with penalties enforced to bring violators to bear the brunt of their transgressions, many residents would be motivated to follow personal hygiene details for timely waste clearance. The question then is where do residents dump their wastes - especially domestic wastes? The sad conclusion is that Nigeria's urban centres and activity nuclei are inundated with solid wastes because of inadequate preparations for their removal, especially in far away and negligible dumpsites not easily accessible. There are few or no collective household receptacles for tenants and landlords to use for regular waste control disposal. There are very few or no designated zones along neighborhood streets to dispose household wastes. In the emanating confusion, regardless of the impact of infrequent environmental sanitation exercises, urban residents dump solid wastes carelessly or haphazardly - anywhere they deem fit. Such controversial tendencies and attributes would seem incomprehensible; if we desire to live in beauteous environments.

The lagoon front at Iddo-Lagos State for instance has been turned into a dump for human and all sorts of solid waste. Trucks fully loaded with feces queue up in large numbers to discharge the contents into the lagoon (Njoku 2006). Environmental experts are of the view that the implication of this practice is very grave. They believed that besides endangering the life of the fishes, dumping of human and other solid wastes into the lagoon breads a plethora of waste-borne diseases.

The failure of relevant agencies to stem the tide of reckless waste dumping and littering of our cities' infrastructure (streets and roads) and surrounding bushes indicate a clear pattern of non-enforcement or non-implementation of existing environmental sanitation laws. The result and effects have been the acceleration of urban decay and its associated tendencies; especially of flight by the upwardly mobile inner city residents to the suburbs.

Aside the impact of abandoned heaps of solid wastes on the environment, one factor stands out - that is, urban decay as a social disorder. It is important to note that its eradication require new skills and technology which must be studied, understood, and implemented in order to bring about clean air and safe drinking water.

Cities in Nigeria are critically affected by huge population fallouts, inadequate supplies of social amenities, and the inability of administrators to meet with the demand of expanding population clusters critically affect Cities in Nigeria. Irregular and unplanned dumping of solid wastes, especially at night, which are often in gross violation of relevant rules and regulations continue to hinder plan preparations and effective land use delineation which were expected to usher in a beautiful, clean and orderly environment.

Consequently, there remains a huge gap between policy formulation, execution and implementation which exacerbate the problem of solid waste management in Nigerian Cities.

\section{Objectives}

The purpose of the paper is to find a solution to the high incidence of uncleared solid wastes build up in cities in Nigeria. The challenges facing relevant authorities, institutions and individuals include as follows:-

i. Avoidance of the calamitous effect of uncleared and untreated solid wastes on the urban landscape.

ii. Stemming the tide of complete blockages of drainage channels by undisposed solid wastes, which also impede traffic and cause traffic congestion.

iii. Allowing uncleared refuse heaps to cause floods and impede social mobility patterns in our cities.

iv. Allowing the high rate of solid waste build up to devalue properties in several locales in urban centres. 


\section{METHODOLOGY}

This paper takes a critical view of the current debate over mounting and uncleared solid wastes in our cities and combines both primary and secondary data with field survey in a search for enduring solutions to the social menace.

Most Nigerian cities, which exhibit untrammeled growth in population agglomeration, are challenged by housing densities which account for the recurrence of uncleared solid wastes. which impact are more prevalent in cities with sharp land use delineation, such as- (i) Central Business Districts (CBDs); (ii) Open Markets; (iii) Civic Centres (iv) Old and New Residential Neighbourhoods and (v) Basic Infrastructures. One common feature of cities like Lagos , Kano, Kaduna, Ibadan, Warri, Aba , Osogbo, Port Harcourt, Calabar, etc is the high volume of traffic generated by urban residents as a result of their social mobility patterns. Such large scale movement is thus normative of urban residents with high population and housing densities who must indulge in unavoidable socialspatial movement as a result of their daily activities.

Urban residents assert a lot of pressures on existing and limited social services so that adequacy ratios in social services delivery easily fall short of expected ceilings. Consequently, the effect of inadequate planning and ineffective land uses, have in no small way accelerated the emergence of urban slums or squatter settlements.

\section{STUDY AREA AND IMPACT}

A number of studies have been conducted on solid wastes and their impact on environment, especially in major urban centres worldwide. Today, timely solid wastes clearance is a major concern for both the developing and developed economies. Mounting refuse heaps are however common features of poor countries, especially in the third world, African and Asian countries being more circumspect in the area of environmental degradation problems.

According to a study done by Egunjobi (1986), the problem of effective solid waste management has to do with poor social services delivery efforts which cause unnecessary delays in solid waste clearance. It is either broken down machinery, non-maintenance of dumpsters, poorly maintained urban streets and roads and irregularities in the designation of sanitary land fills sites. Egunjobi's study covered the cities of Lagos, Ibadan and Sokoto.

In the same vein, Adesina (1983) observed that the process of urbanization in developing countries has led to unexpected movement of persons in large numbers to the cities, causing related problems of congestion, scarcity and dilapidation - all being residual features of urban decay. The main connection in Adesina's study is the impact of solid wastes on sudden agglomeration of residents in cities.

Onokerhoraye (1977) in his study related the issue of the decomposing uncleared solid wastes in our urban centres to lack of comprehensive land use system which extols the values of urban planning and environmental quality. He asserted that poorly maintained winding streets and roads do not give room for the efficient evacuation of solid wastes to incineration centres at the outskirts of cities.

The observation of these proponents of environmental sanitation leads to only one conclusion - that rapid urbanization has resulted in inadequate responses to the dumping of refuse along city streets, in burrows or erosion impacted terrains, and river beds or flood basins. These features of indiscriminate waste dumping reduce invariably the capacity of the rivers and rivulets to dispose storm runoffs along their drainage channels.

A confirmed study done by Abumere et al. (1983) looked at the magnitude of solid waste generated annually in Nigeria and blamed the net effect on the oil boom recorded since 1970 . He averred that there has to be a link between solid wastes generation and the rapid rise or rate of population growth in our cities. In the study, the fear of a lack of strategic measures for solid waste management would ensure that the level of wastes generation could use up to 50 million tons by year 2010 .

The United Nations study (1991) raised an alarm over the susceptibility of urban social services delivery, particularly access to water, to the domestic and industrial pollutants.

Similar concerns over water pollution were raised by Akintola and Areola (1980). However, Omuta (1985) would conclude that despite the rate of advancement in technology in developing nations, the issue of solid waste disposal remains worrisome and detrimental to human 
settlement, environmental quality, safety and security of urban residents.

\section{Urban Solid Waste Generation}

As cities grapple with solid waste disposal and management, concerns over environmental degradation have remained unabating. The urban landscape is characterized by various socio-spatial needs and mobility requirements. Cities are centres of dynamic change where residents exhibit classical and typical tendencies in land use activities which help to define their mode of living - quality of life as well as sustenance of specific lifestyles. The amount of solid waste generated is congruent with the population density within each environment (see Tables 1 and 2 ).

Table 1: Population and solid wastes generated in some Nigerian urban centres

\begin{tabular}{lcrc}
\hline $\begin{array}{l}\text { City } \\
\text { /Town }\end{array}$ & $\begin{array}{l}\text { Population } \\
\text { x 1000 }\end{array}$ & $\begin{array}{l}\text { Solid wastes } \\
\text { (kg/year } x \\
\text { 1000) }\end{array}$ & $\begin{array}{l}\text { Generation } \\
\text { rate }(k g \\
\text { capacity / } \\
\text { year })\end{array}$ \\
\hline Lagos & 4000 & $450,331.13$ & 112.58 \\
Ibadan & 2200 & $284,106.00$ & 129.14 \\
Kano & 2000 & $218,543.05$ & 109.27 \\
Kaduna & 1600 & $349,668.90$ & 218.54 \\
Osogbo & 800 & $113,907.30$ & 142.38 \\
Aba & 800 & $100,662.30$ & 235.83 \\
Warri & 400 & $91,390.73$ & 228.48
\end{tabular}

Source: Data from United Nations Statistical Year Book Quoted from Nigeria Population 1991 Census Released in April 1992

Table 2: Solid waste $(\mathrm{kg} / \mathrm{yr} \times \mathrm{1000})$ generation in some Nigerian urban centres

\begin{tabular}{|c|c|c|c|c|}
\hline Cities & 1982 & 1985 & 1990 & 2000 \\
\hline Lagos & 625,399 & 681,394 & 786,079 & 998,081 \\
\hline Ibadan & 350,823 & 382,224 & 440,956 & 559,882 \\
\hline Kano & 319,935 & 348,580 & 402,133 & 535,186 \\
\hline Kaduna & 257,879 & 280,925 & 324,084 & 431,314 \\
\hline Onitsha & 242,240 & 263,929 & 300,477 & 386,593 \\
\hline $\begin{array}{l}\text { Port- } \\
\text { Harcour }\end{array}$ & t 210,934 & 229,821 & 265,129 & 236,853 \\
\hline Aba & 131,190 & 143,712 & 169,719 & 236,703 \\
\hline Gusau & 44,488 & 48,471 & 57,243 & 79,835 \\
\hline
\end{tabular}

Source: Nigerian Environment Study Action Team (NEST, Ibadan 2001). Published in the Sunday Vanguard, January 14, 2007, P 15.

If then urban solid wastes generation in Nigeria reflect divergent lifestyles and social stratification, the degree of variance can directly be traced to the food we eat; the quantity and type (organic), and household goods (inorganic); and method of disposal so as to limit the challenges to the health and safety of urban residents in general

The main factors influencing fast generation of waste, which pollute the land, are population, phenomenal urban growth due to rural-urban migration (Dimuna 2004).

\section{Techniques of Solid Waste Disposal Management}

The known or popular means of solid waste disposal or management are (1) refuse composting (2) incineration and (3) sanitary landfill/ dumpsites.

Refuse composting requires on the one hand, relatively high temperature for mechanical composting, while on the other hand, the most notable process in rural and urban areas involves dug pits, wherein the collected refuse are disposed off to rot or ferment. The end product is called "compost" and used as common manure in farms. A variant of composting is compacting or solid wastes reduction through mechanical process of 'squeezing' to ensure smaller sizes and packages which enhances disposal/management time and space.

The other method is incineration. This process involves burning of collected solid wastes from households, offices and markets. The main objective being size reduction and conversion of refuse to other uses without grossly affecting the environment. The only slight draw back of solid waste incineration is the stench or odour emanating from there. Waste incineration is a much easier process because of dryness and easier combustion.

The third variety in solid waste management is the sanitary landfill. This is a process of collecting solid wastes and conveying them by using vehicle, heavy duty dumpsters, lorries and tippers to designated dumpsites. The accumulating wastes are carefully and concisely laid or layered into specified depression or valleys or dug borough pits (as sites) with the intent to fill and reclaim these exact locations for future uses.

In our environment, we easily claim the use of land topography ravaged by gulley erosion. The main impetus of this kind of adaptation is cost consideration and opening another pit to cover an old pit. But by the use of hallow channels, which ordinarily would have served as flood 
channels, so much money and energy are saved in the process. The only involvement is the damming of both ends of the desired portions to be used in the dumping operation.

Reducing the nuisance and hazards of indisposed solid wastes (by clearing or removing them) to remote sanitary landfill sites, is one less expensive way to save the government and public from the additional strictures of environmental degradation.

\section{Municipal Solid Waste Management (An Environmental Sanitation Day Model)}

The Nigerian situation exhibits tenets of diverse socio-cultural behaviours, often laden with cultural implications which stress solid wastes avoidance rather than minimization and control. To this effect, the Federal Government establishes an Environmental Sanitation Edict in 1972-73 Plan Period. The force behind the idea was to generate awareness and enhance enthusiasm among the citizenry and particularly our youth. This is to dedicate one day in a month as a civic responsibility toward the cleaning and beautification of our surroundings. Thus, the last Saturday of every month was chosen for all citizens of Nigeria to come out enmass to clean their surroundings between 7.00am - 10.00am in compliance or observance of a National Environmental Sanitation Day. Residents are made to come out to clean Roads and streets, neighbourhood surroundings, drainage channels, linking markets centres, public buildings, etc. Domestic solid wastes, such as kitchen wastes, commercial and industrial wastes, outdoor wastes were also gathered and disposed accordingly. Movement was prohibited, except on emergency cases or essential duties.

Despite the one-day-a month national sanitation day / exercise, there are those who generate wastes and do not know where to dump them. And there are still those may know where the sites are located but find them too far away or do not have the means or the alternative method of disposal. They, therefore, indulge in haphazard dumping of non hazardous solid wastes at night and in isolated spots in Cities without deterrence.

As a result of non-conformance and noncompliance to existing laws and poorly coordinated municipal solid wastes clearance scheme, uncleared refuse heaps still inundate our activity nuclei, viz. markets, shopping centres, civic centres, public fields, residential neighbourhoods etc. Even then, the monthly oneday Saturday weekend is too minimal and insufficient to combat the rate of the wastes build up so that the uncollected garbage from residential units and drainage channels return to existing status or form. The markets for example, remain filthy because of uncleared solid wastes. Therefore, the chain or cycle of event is too distant and disconnected to have any meaningful impact. It is also noteworthy that there are often no credible designated sanitary landfill sites. The net effect is confusion and failed attempts at locating the designated zones in use at any point in time.

\section{Opportunities and Challenges in Solid Waste Management}

The rising incidence of solid waste build up in several urban centres in Nigeria is not peculiar to Nigeria cities alone. Other cities worldwide encounter the same problems but proffer faster clearance details or measures. It then becomes obvious that part of our problems here is attitudinal and psychological rather than being a crucial bye-product of false urbanization.

According to Wikipedia (2009), waste management practices differ for developed and developing nations, for urban and rural areas, and for residential and industrial producers. It states clearly that management for non-hazardous residential and institutional waste in metropoli$\tan$ areas is usually the responsibility of local government authorities, while management for non-hazardous commercial and industrial waste is usually the responsibility of the generator.

However, in the case of Nigerian cites, local government authorities are unable to cope with the rate of soli waste build up and thus, lack the capability and the technical knowledge to combat the situation. Individuals struggle with their household waste, not knowing where to put their waste as there are no official waste bins located nearby to ease disposal. Uncleared garbage, even with the introduction of publicprivate sector partnership (PPP) initiative, remains a challenge to both individuals and municipal authorities.

Consequently most cities in Nigeria, especially Lagos, Kano, Ibadan, Aba, Warri , Benin , Onitsha, etc. suffer from a prolongation of culture of clutter because of the non-existence of 
enforceable land use and zoning laws. As a result solid waste management has become a source of worry to many Nigerians especially those living in the city of Lagos. According to Smith (2007), solid waste management in the city of Lagos is taking a new dimension because of the improvement of the activities of the Lagos State Waste Management Agency (LAWMA). She observed that since the inception of the organization, a lot of filthy, dirty and unhygienic way of disposing waste in some major parts of the state has reduced to its barest minimum. This is in line with the global trend in solid waste management which draws the link between the collection, transportation, processing, recycling or disposal, and or monitoring of waste materials (Wikipedia 2009).

The state of unplanned growth and development of cities in Nigeria has compounded the issue of timely waste clearance. A habit of cleanliness begins from our homes. But sadly, in most Nigerian cities squatter settlements are predominant and area residents have no easy access to waste receptacles to dispose of their garbage which underscore the irregular, unwholesome dumping of refuse at most street functions in overbuilt and unserviced residential neighbourhoods as well as inner city business nuclei.

Another challenge facing urbanities is the nature of traffic flows or spatial mobility patterns which causes congestion to pedestrian and vehicular movement and impact negatively on the ability of city administrators and planners to control urban housing growth and development. Several Nigerian cities have roads and streets that are disjointed, narrow and winding. These road networks are not adequately planned with enough width and space for sidewalks; double lanes for ensuring through traffic; speed limits etc.

Given these severe cases of traffic impedance, there is a proliferation of haphazard dumping of non hazardous and hazardous domestic, commercial and industrial waste materials. In addition, the introduction of private waste collectors who collect money for a specific volume of waste generated, has not given enough relief nor reduced the accumulation of solid waste in urban neighourhoods.

The rate of accumulation of solid wastes in cities remain a challenge because there exist a lack of personal commitment and use of opportunities within area residents who in turn blame city officials for not providing mobile and lidded waste bins close to sidewalks or curbs in their residential zones.

\section{Meeting Municipal Solid Waste Management Challenges in Urban Centres}

Emerging cities in developing economies like Nigeria exhibit features of unplanned growth, population explosion and informal settlement leading to an irregular build up of solid waste begging for timely clearance or disposal and treatment in order to reduce their hazardous effect on residents and enhance rather demean the quality of our environment needs to be tackled frontally, systematically, in an all embracing manner.

Past independent, individual, commercial and industrial responses to waste generation and control have not yielded positive results. Therefore we need to employ a more integrated approach which would combine a life cycle analysis with modern method or waste disposal through composting, incineration and recycling for energy, chemical and other positive uses. A life cycle analysis (LCA) simply indicate that waste administration need to follow a path of source separation, collection, reuse, recycling of the non organic waste and energy and compost fertilizer production of the inorganic waste via anaerobic digestion (Wikipedia 2009).

In many Nigerian cities, scavenging, which is the business of picking scraps from refuse dumps for sale is thriving. Ordinarily, considered a dirty and demeaning job because of the dirty nature of the dump site coupled with the offensive stench and gaseous emissions they produce while valuable scraps are being sorted, scavenging is generally regarded as a business of last resort for those engaged in it. But as dirty as is the business, those engaged in it are surprisingly making fortunes and smiling to the banks. The large number engaged in it undermines the fact that the business is lucrative for the operators, especially since there is ready market for scrap items. They buyers in turn sell to companies, which recycle them as raw materials for the production of new products (Adegboye 2006).

Recycling is very popular among developed countries, which have long realized that waste is not necessarily a wasteful - it can be turned 
into money. Recycling, according to (Wikipedia 2009) report, is in most developing countries, the widespread collection and reuse of everyday waste materials such as empty beverage containers. These are collected and sorted out into common types so that the raw materials can be reprocessed into new products. Recycling is something that Nigerians must come to terms with if we are to adopt an integrated solid waste management approach. The most commonly recycled consumer products in Nigerian cities are aluminum beverage cans, steel food and aerosol cans, plastic and glass bottles and jars, paper board cartons, newspapers, magazines, fibre boards, etc. Sorted waste can do the following:

- It can become raw materials

- It can lead to self-reliance

- It can improve physical and

environmental health

- It can provide gainful employment

- It can help to establish more raw materials for processing in factories

- It can help establish recycling plants.

Currently, Lagos State Government through its Waste Management Authorities (LAWMA) launched its new waste recycling management initiative when it unveiled two communal waste recycling banks in an effort to deal with over 9,000 tons generated daily. The scheme will encourage communities in the state to partner with the agency to sort waste in furtherance of its waste to wealth programme.

Under the new scheme, 1,000 locally manufactured waste banks, strategically located in neighbourhoods across the state, will enable residence to submit their already sorted household waste for categorization - that is, portions for used clothes, electronic waste, glasses, plastic materials, cans, etc. In addition, the sorting is to be supervised by trained waste resource managers. After which, the sorted or categorize wastes would be transfer to loading stations (Vanguard Newspaper 2010)

\section{CONCLUSION}

A number of social disorders have been found to accelerate the decay of major activity nuclei, particularly residential neighbourhoods in cities. The resultant effect is a rising incidence of non-conformance to enabling environmental protection or safety regulations. Consequently, the culminating effects of long violations cause severe environmental degradation: while the gaps in resources allocations remain widespread and challenging for concise problem solving measures. Certainly, the hazard associated with the lax and time lag in disposing solid wastes is thus a challenge to all stakeholders - especially public officials who must provide leadership, capacity building and funding or capital formation to facilitate and renew community service to ensure smooth social services delivery to all.

The issue of reduction of solid wastes from our cities has remained a major challenge to urban beautification and safety of the entire urban landscape. There must be put in place a concerted approach to waste avoidance, minimization and reduction through modern methods of waste management and disposal using the right mix of strategies sustainable in our environment. There remains an urgent need for sustainability of a clean environment, better living conditions through awareness campaigns, public lectures to ensure a better way to live.

Any sanitation or beautification exercise should ensure the removal of refuse heaps and reduction of their offensive odour emanating from uncleared solid wastes. Invoking the Clean Air and Health Acts of 1964-68 are crucial in terms of making waste reduction a daily routine in our societies.

In addition, effective penalties must be invoked and culprits punished, so that the enforcement of proper practices are not left to area wide waste management authorities alone. An effective chain in the cycle of timely clearance to designated landfills, dump sites, for incineration and compacting and composting should be integrated into energy and the land reclamation schemes envisioned in the future.

\section{REFERENCES}

Abumere SI, Filani MO1988. Forecasting Solid Waste Magnitude for Nigerian Cities, Paper Presented at the National Conference on Development and Environment, NISER, Ibadan 1988.

Adegboye Kingsley 2006. Scavenging 2006: Making a "Lucrative" Living from a Hazardous Dump Sites. Vanguard, Tuesday, February28, 2006, P. 36.

Adesina HO 1983. Urban environment and epidemic diseases. In: EA Adeniyi, IB Bello Imam (Eds.): Proceedings of National Conference on Development and Environment. Ibadan: NISER, pp. 234-256.

Akintola FO, Areola D 1980. Domestic water consumption in urban areas: A case study of Ibadan City, Nigeria. Water Supply and Management, 4: 313321. 
Adedibu AA 1985. A comparative analysis of solid waste composition generation in two cities of a developing nation. The Environmentalist, 5(12): $89-103$.

Adegoke OS 1989. Waste Management within the Context of Sustainable Development. Proceedings of the Environment and Sustainable Development in Nigeria Workshop, 25 - 26 April, Abuja Nigeria, pp. $103-110$.

Agunwamba 1998. Solid waste management in Nigeria problems and issues. Environmental Management, 22(6): 849 - 856

Burgess EW 1925. The growth of the city. In: RE Park, RD Mackenzie (Eds.): The City. Chicago: University of Chicago Press, pp. 56-72.

Dimuna KO 2004. The problem with the management of environmental pollution in Nigeria. Journal of Applied and Basic Sciences, 2(1\&2): 5-9.

Egunyobi TO 1986. Problems of solid wastes management in Nigeria urban centres. In: EA. Adeniyi, IB Bellow Imam (Eds.): Proceedings of National Conference on Development and Environment. Ibadan: NISER, pp. 74-92.

FEPA 1998 (Federal Environmental Protection Agency). 1989. National Policy on the Environment. Nigeria: FEPA, P. 22.

FRN (Federal Republic of Nigeria) 1991. Official Gazette 78 (42): B15 - B37.

Federal Military Government 1988. Federal Environmental Protection Agency Decree No. 58: A 911 - A 932.

NEST: Nigerian Environment Study Action Team (NEST, Ibadan 2001) 2007. Sunday Vanguard, January 14, 2007, P 15.

Njoku Jude 2006. Iddo: Where human waste is dumped with impunity. Vanguard, Monday, September 18, 2006, P. 42.

NISP 2003. Nigeria Institute of Safety Professionals NISP 2003. Contractor Employee HSE Training Manual Level 3. Harcourt: ECNEC Ltd.

Omuta GED1985. Urban solid wastes generation and management towards an environmental sanitation policy. In: PB Sada, RD Odemerho (Eds.): Environmental Issues and Management in Nigeria Development. Benin: University of Benin, pp.57 -59 .

Onokerhoraye AG 1977. Public involvement in urban development planning: The case of environmental development planning sanitation in Ibadan, Nigeria. Journal of Administration Overseas. 10: $171-177$.

Okecha SA 2000. Pollution and Conservation of Nigeria Environment. T Afrique International Associates Owerri Nigeria.

Smith Rita 2007. Lagos: Dramatic Turnaround in Waste Management. Daily Independent Friday March 9, 2007, P. 11.

Singh SK 1998. Solid waste management: An overview of environmental pollution. Environmental Control Journal, I(3): 50-56.

Uwaegbulam Chinedu 2004. World is meeting goals of safe drinking water but falling behind on sanitation, says UN. The Guardian, Monday, August 30, 2004. P. 50.

Vanguard Newspaper 2010. Lagos Unveils New Waste Recycling Schemes Thursday December 23, 2010. P. 8 .

Waste Management- From Wikipedia the free encyclopedia 2010. From http://en.wikipedia.org/wiki/ Waste_management (Retrieved on 11/22/2010). 